\title{
É POSSÍVEL OBSERVAR A INTERFERÊNCIA DE ONDAS MECÂNICAS UTILI- ZANDO CAIXAS DE LEITE?
}

\author{
Thaianne Lopes De SouzA ${ }^{1,2}$, Paulo Alexandre De Castro ${ }^{1,3,4}$
}

\author{
1. Departamento de Física, Universidade Federal de Goiás \\ Av. Dr. Lamartine Pinto de Avelar, 1120 - Setor Universitário - CEP 75704-020 - Catalão - \\ GO \\ E-mails: thaiannefisica@gmail.com, padecastro@ufg.br
}

2. Mestrado em Ensino de Ciências e Matemática, Universidade Federal de Uberlândia

Campus Santa Mônica - Bloco 1 A - Sala 207A - Av. João Naves de Ávila, 2121 - CEP: 38408-100 Uberlândia $-M G$

3. Mestrado Profissional em Ensino de Física, Universidade Federal de Goiás Av. Dr. Lamartine Pinto de Avelar, 1120 - Setor Universitário - CEP 75704-020 - Catalão - GO

4. Mestrado Profissional em Gestão Organizacional, Universidade Federal de Goiás

Av. Dr. Lamartine Pinto de Avelar, 1120 - Setor Universitário - CEP 75704-020 - Catalão - GO

\begin{abstract}
In this work, we present and discuss the assembling of an experiment, low cost, through which looked easy and qualitatively the physical phenomena of diffraction and interference. Our proposal to use low cost experiment to check the phenomena of diffraction and interference, came the great difficulty of the high school teachers to address minimally satisfactory phenomena that occur with mechanical waves, such as diffraction and interference. Usually the assembly of an experiment to present these phenomena have a relatively high costs, and yet, the materials are not always easy to acquire, as is the case for traditionally made experiments in schools and universities that use an overhead projector, tank of glass and with zinc or iron plates. In this paper, we show how it is possible to construct an apparatus using only 2 box of milk (long life), 4 paper clips, one sachet of powdered gelatin and spoon, with which it is possible to check visually the diffraction and interference.
\end{abstract}

Keywords— low cost experiment, teaching physical, mechanical waves, interference phenomenon.

Resumo- Neste trabalho, apresentamos e discutimos a montagem de um experimento, de baixo custo, por meio do qual verificamos de modo fácil e qualitativo os fenômenos físicos de difração e interferência. Nossa proposta, de usar experimento de baixo custo, para verificação dos fenômenos de difração e interferência, surgiu da grande dificuldade encontrada pelos professores do ensino médio em abordar de maneira minimamente satisfatória fenômenos que ocorrem com ondas mecânicas, tais como difração e interferência. Usualmente a montagem de um experimento que apresente esses fenômenos tem um custo relativamente alto e, ainda assim, os materiais nem sempre são fáceis de se adquirir, como é o caso de experimentos tradicionalmente feitos em colégios e universidades que se utilizam de um retroprojetor, cuba de vidro e anteparos de zinco ou ferro. Neste trabalho, mostramos como é possível construir um aparato utilizando apenas 2 caixas de leite (longa vida), 4 clipes para papel, um sachê de gelatina em pó e uma colher, com o qual é possível a verificação de difração e interferência.

Palavras-chave— experimento de baixo custo, ensino de física, ondas mecânicas, fenômeno de interferência.

\section{Introdução}

Os fenômenos ondulatórios possuem grande destaque na natureza, uma vez que são vários fenômenos da natureza que precisam ser descritos por conceitos ondulatórios. Alguns desses fenômenos estão presentes na maioria das atuais tecnologias. Destacam-se aqueles relacionados à transmissão de informação, por exemplo, o som, a luz e as ondas eletromagnéticas. Os principais sistemas ondulatórios presentes no nosso cotidiano são resultados da propriedade da superposição das ondas, dos quais resultam dois fenômenos característicos, a interferência e a difração.
A importância do estudo de fenômenos ondulatórios tem sido destacada por vários autores, como podemos verificar através do testemunho do Gaspar (Vicenzi et al., 2007): "[...] O conhecimento da óptica ondulatória é essencial, sobretudo para a compreensão das ideias físicas modernas. Por exemplo, a experiência da fenda dupla de Young é básica para a compreensão do enigmático caráter dual da luz".

A difração pode ser definida como um fenômeno que ocorre quando uma onda consegue atravessar (ou contornar) um obstáculo (Halliday et. al., 2002). conforme Figura 1.

É comum que se confunda a definição de interferência e a definição de difração, uma vez que ainda não se descobriu uma diferença importante entre 
ambos os conceitos. Sendo assim, diz-se que quando há poucas fontes interferindo, então o resultado geralmente é denominado interferência, contudo se houver um grande número de fontes, o termo mais utilizado popularmente é difração. Subentende-se que difração pode ser uma continuação direta do estudo da interferência (Feynman et. al., 2008). Torna-se importante ressaltar a dependência da interferência em relação ao comprimento de onda proporcionada.

A difração exerce um papel fundamental na formação das imagens geradas nas mídias atuais. Contudo, sua importância na maioria dos fenômenos da natureza tem sido desprezada e pouco abordada. Observamos tal fato pela deficiência da abordagem da difração e interferência no ensino médio, que tem perdido espaço para outros fenômenos considerados mais importantes ou de grande relevância, isto é, não conquistou seu espaço nos currículos escolares.

Como a difração é um fenômeno pouco abordado no Ensino Médio, tencionamos neste trabalho estudar a difração de ondas mecânicas por meio da realização de um experimento de baixo custo, para que seja possível e acessível, aos alunos de Ensino Médio, construir, desenvolver e, o mais importante, compreender em sua plenitude o fenômeno de difração.

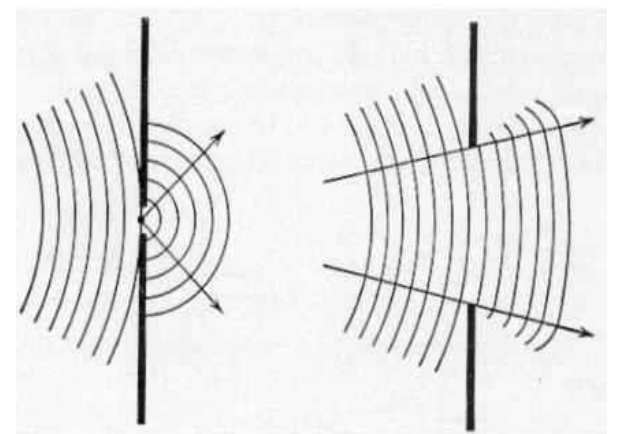

Figura 1. Fenômeno da difração na água. Dependência da melhor visibilidade deste fenômeno de acordo com a espessura da abertura da fenda.

\section{Materiais utilizados e metodologia}

Para a realização deste experimento usamos os materiais listados na tabela abaixo:

Tabela 1. Materiais utilizados para montagem do experimento de baixo custo.

\begin{tabular}{l|l}
\hline Quantidade & Item \\
\hline $\mathbf{2}$ (duas) & Caixa de leite \\
$\mathbf{1}$ (um) & Sachê de gelatina \\
$\mathbf{4}$ (quatro) & Clipe para papel \\
$\mathbf{1}$ (uma) & Colher de sopa \\
\hline
\end{tabular}

\subsection{Primeira tentativa de construção do experimento}

Na primeira tentativa de construção do nosso experimento, fizemos uma abertura na parte frontal (dimensões de largura $\mathrm{x}$ altura) de uma das caixas de leite. Na segunda caixa de leite, recortamos dois anteparos: a tampa e o fundo (dimensões de largura $\mathrm{x}$ profundidade) da caixa de leite.

No primeiro anteparo foi recortada uma fenda e no segundo foi feito duas fendas. Inicialmente, estes anteparos foram colocados muito distante um do outro e, por isso, tivemos dificuldades para as ondas longitudinais atravessarem a primeira fenda do primeiro anteparo e em seguida as duas fendas do segundo anteparo e gerar o efeito de interferência no terceiro anteparo (fundo da caixa). Para contornar o problema, tentamos aproximar os anteparos, porém novamente obteve-se dificuldade das ondas ultrapassarem as fendas. Com isso, mais uma vez, não conseguimos fazer com que as ondas ultrapassassem o primeiro e o segundo anteparos para que pudessem observar o padrão de interferência no fundo da caixa de leite.

Depois de refletir sobre o que poderia estar ocorrendo de errado, ocorreu-nos que o problema poderia estar relacionado a espessura das fendas nos anteparos, que era muito grande em vista do comprimento de onda que estavam sendo produzidas, logo as fendas deveriam ter uma abertura menor, para que o fenômeno de interferência pudesse ser observado. Para facilitar um pouco mais a realização do experimento, tornamos os dois anteparos (com fendas) móveis.

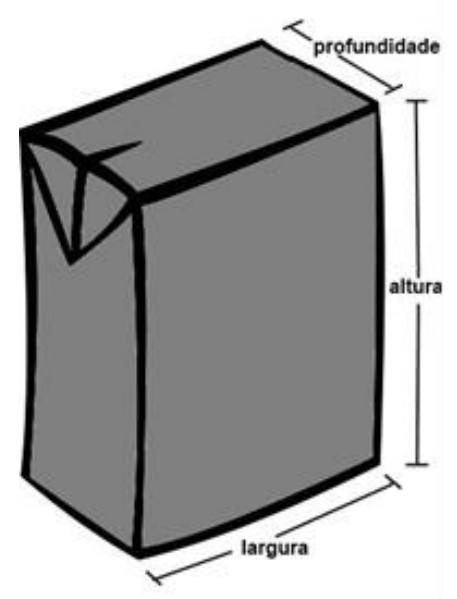

Figura 2. A caixa de leite utilizada neste experimento de ondas mecânicas possui as seguintes dimensões: $17 \mathrm{~cm}$ de altura, $10 \mathrm{~cm}$ de largura e $7 \mathrm{~cm}$ de profundidade.

\subsection{Segunda tentativa de construção do experimento}

Depois de constatarmos os problemas na primeira tentativa, começamos do zero. Pegamos uma nova caixa e fizemos uma abertura na parte frontal (dimensões de largura $\mathrm{x}$ altura). Com outra (segunda) caixa de leite, construímos os dois anteparos (com fendas) móveis. Os anteparos possuíam as seguintes 
características: o primeiro anteparo possui uma fenda de $3 \mathrm{~mm}$ de espessura e o segundo anteparo possui duas fendas de $3 \mathrm{~mm}$ de espessura cada, que distam aproximadamente $10 \mathrm{~mm}$ uma fenda da outra. Estes dois anteparos foram colocados a aproximadamente $20 \mathrm{~mm}$ de distância um do outro.

Após os anteparos estarem presos por clipes na caixa de leite, enchemos a caixa com a água, já com o corante (gelatina), deixando a água com corante repousar até que não se perceba nenhum movimento da água dentro da caixa. E então, bem em frente do anteparo com apenas uma fenda, realizamos o movimento, repetido e rapidamente, de afundar e retirar o cabo da colher da caixa de leite com água, fazendo com que fossem produzidas ondas circulares.

\section{Resultados e discussão}

Depois da, bem sucedida, segunda tentativa em construir o experimento para o estudo qualitativo dos fenômenos de difração e interferência, verificou-se que as ondas produzidas com o cabo da colher conseguiram ultrapassar ambos os anteparos/barreiras e produziram o padrão de interferência no terceiro anteparo. Parte do mérito dessa visualização se deve ao fato de utilizarmos o corante na água.

É necessário lembrar que, ao realizar este experimento, as condições de espessura das fendas e distâncias dos anteparos supracitadas sejam respeitadas, para que os fenômenos possam ser reproduzidos.
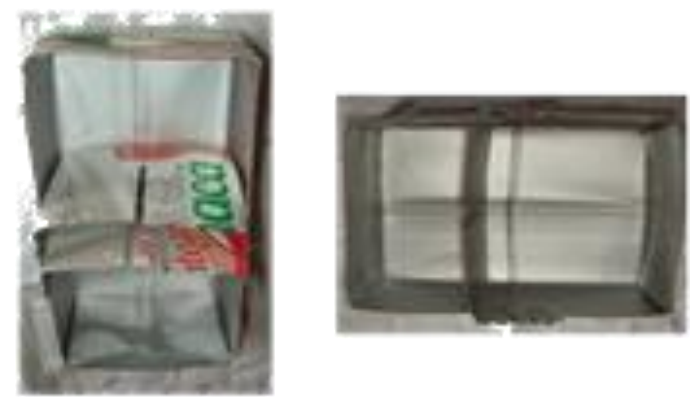

Figura 3. Montagem da caixa para a demonstração do experimento.

\section{Conclusão}

O uso de experimentos é fundamental em Física, são indispensáveis para o cientista. Através dos experimentos consegue-se entender a natureza, descobre seus segredos, além de serem essenciais também para o ensino de Física, porque fascinam, intrigam e podem produzir efeitos duradouros. Vejamos o testemunho do genial físico alemão Albert Einstein (1879-1955):

Quando eu tinha quatro ou cinco anos, meu pai mostrou-me uma bússola. Lembro-me - ou pelo menos creio que me lembro - que essa experiência causou-me uma impressão profunda e duradoura. Devia haver algo escondido nas profundezas das coisas (Einstein, 1982).
Neste trabalho desenvolvemos um experimento que se usa caixas de leite para o estudo qualitativo e demonstração dos fenômenos de difração e interferência. Verificamos que a montagem é simples, facilmente reproduzida por alunos de ensino médio, pode auxiliar na compreensão de fenômenos da física, muitas vezes incompreensíveis num primeiro momento sem o auxílio de um experimento (Heineck, 1999).

Ao se produzir este experimento, o aluno poderá estudar um pouco mais sobre a Ondulatória. Além dos tópicos de difração, ele poderá estudar o comprimento de onda e como isso interfere significativamente para uma boa obtenção de resultados na realização desse experimento. E ainda, poderá estudar sobre interferência de ondas, onde aprenderá a distinguir a interferência construtiva da destrutiva. Assim, num único experimento o aluno poderá estudar vários fenômenos e as implicações destes no mundo que o cerca (Da Rosa e Da Rosa, 2004)].

Além de ajudar significativamente na compreensão de determinado conteúdo, através do uso de experimento de baixo custo, os alunos poderão desenvolver seus próprios métodos de aprendizagem e ainda exercitar a sua criatividade.

Ao usar a experimentação, o professor estará desenvolvendo e melhorando a sua prática docente. Ainda mais, ao se utilizar esses métodos de aprendizagem, o professor estará incentivando os alunos a estudarem fenômenos físicos de forma que seja acessível, compreensível e palpável.

Os materiais como caixas de leite, gelatina, clipes e colher são itens encontrados facilmente em nossas cozinhas. Assim sendo, podemos concluir que o experimento proposto é acessível tanto para os alunos quanto para os professores. Além dos excelentes resultados qualitativos, serve para os alunos e professores abram (e mantenham abertas) as "portas da experimentação nas aulas".

\section{Agradecimentos}

Agradecemos a Coordenação de Aperfeiçoamento de Pessoal de Nível Superior (CAPES) pelo apoio financeiro fornecido por meio do Programa Institucional de Bolsas de Iniciação a Docência (PIBID) No 001/2011/CAPES, biênio 2011/2013.

\section{Referências Bibliográficas}

[1] Da Rosa, C. T. W.; Da Rosa, A. B. (2004), A teoria histórico-cultural e o ensino de Física. Revista Iberoamericana de Educación, vol 33

[2] Einstein, A. (1982), Notas autobiográficas. Rio de Janeiro: Nova Fronteira. Tradução de Aulyde Soares Rodrigues. 
[3] Feynman, R. P.; Leighton, R. B.; Sands, M. (2008), The Feynman Lectures on Physics, Vol. 1, Editora Bookman.

[4] Halliday, D.; Resnick, R.; Walker, J. (2002), Fundamentos de Física, Vol. 2, $6^{\text {a }}$ Edição, LTC Editora, Rio de Janeiro, RJ.

[5] Heineck, R. (1999), O Ensino de física na escola e a formação de professores: reflexões e alternativas. Caderno Brasileiro do Ensino de Física, vol 16, no 2.

[6] Vicenzi, S.; Cunha, S. L. S.; Libardi, H. (2007), Ensinando Difração para alunos do Ensino Médio. XVII Simpósio Nacional de- 